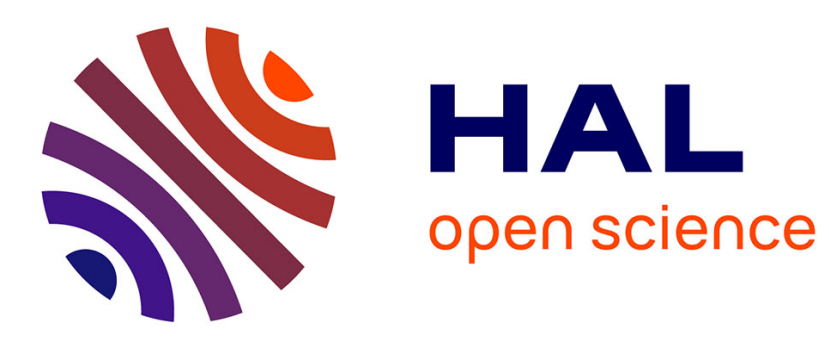

\title{
Losses in high quality quartz crystal resonators at cryogenic temperatures
}

\author{
S. Galliou, J. Imbaud, M. Goryachev, R. Bourquin, P. Abbe
}

\section{To cite this version:}

S. Galliou, J. Imbaud, M. Goryachev, R. Bourquin, P. Abbe. Losses in high quality quartz crystal resonators at cryogenic temperatures. Applied Physics Letters, 2011, 98 (9), pp.091911 - 091911-3. 10.1063/1.3559611 . hal-00660543

\section{HAL Id: hal-00660543 https://hal.science/hal-00660543}

Submitted on 21 Apr 2021

HAL is a multi-disciplinary open access archive for the deposit and dissemination of scientific research documents, whether they are published or not. The documents may come from teaching and research institutions in France or abroad, or from public or private research centers.
L'archive ouverte pluridisciplinaire HAL, est destinée au dépôt et à la diffusion de documents scientifiques de niveau recherche, publiés ou non, émanant des établissements d'enseignement et de recherche français ou étrangers, des laboratoires publics ou privés. 


\title{
Losses in high quality quartz crystal resonators at cryogenic temperatures
}

\author{
Serge Galliou, ${ }^{\text {a) }}$ Joël Imbaud, Maxim Goryachev, Roger Bourquin, and Philippe Abbé \\ Department of Time and Frequency, FEMTO-ST Institute, ENSMM, 26 Chemin de l'Epitaphe, 25000 \\ Besançon, France
}

(Received 15 December 2010; accepted 3 February 2011; published online 3 March 2011)

\begin{abstract}
Measurement of the mechanical losses of quartz crystal is a topic of interest for communities dealing with the gravitational wave detectors and also the time and frequency domain. About the latter, the authors describe $Q$-factor measurements of quartz crystal resonators at cryogenic temperatures under $10 \mathrm{~K}$, thanks to a cryocooler-based experimental set-up. A $Q$-factor of 325 millions at $4 \mathrm{~K}$, on the fifth overtone of the quasilongitudinal mode at $15.9 \mathrm{MHz}$, has been recorded. As shown, the acoustic wave trapping is suspected to limit the Landau-Rumer regime below $6 \mathrm{~K}$ [Landau and Rumer, Phys. Z. Sowjetunion 11, 18 (1937)]. () 2011 American Institute of Physics.
\end{abstract}

[doi:10.1063/1.3559611]

Mechanical losses of quartz crystal at cryogenic temperatures are still a topic of interest for at least two scientific communities. The first community dealing with gravitational waves uses crystalline quartz since a couple of years. Materials with high quality-factors $(Q$-factors $)$ at low temperatures are needed to improve the sensitivity of optical detectors. ${ }^{1,2}$ Crystalline quartz revealed to be a good candidate for that use. In this context, $Q$-factors of about 2.5 $\times 10^{7}$ have been measured at $6.5 \mathrm{~K}$ (for z-cut samples with an excited mode close to $6 \mathrm{kHz}$ at $300 \mathrm{~K}$ ) by means of a specific experimental method. ${ }^{3,4}$ The second community is the time and frequency community for which, historically, quartz crystal is the standard material for acoustic resonators. As an example, within a volume lower than $10^{-3} \mathrm{~m}^{3}$, stateof-the-art 5 or $10 \mathrm{MHz}$ ovenized quartz crystal oscillators can exhibit fractional frequency stabilities lower than 8 $\times 10^{-14}$ over $1 \mathrm{~s} .5$ Though conventional devices are designed for working within the ambient temperature range, investigations at low temperature have also been carried out. ${ }^{6,7}$ Recent $Q$-factor measurements of standard resonators at cryogenic temperature are reported in the following sections. There are two motivations: on the one hand, to implement sooner or later a complete cryogenic crystal oscillator in order to reach ultimate frequency stabilities with this type of references, on the other hand, to get data and knowledge about crystal resonators potentialities from these experiments.

In the frequency-source domain, high- $Q$ resonators are achieved with devices smaller than the samples investigated for the gravitational waves interferometers. ${ }^{2,4}$ They are designed to confine the vibration thanks to a planoconvex shape. ${ }^{8}$ This trapping allows reducing the resonator's diameter without increasing the mechanical losses due to the mounting. Moreover they are optimized to operate on a thickness shear mode (namely the C-mode, usually at 5 or 10 $\mathrm{MHz}$ ), that exhibits a frequency-temperature turnover point close to $85^{\circ} \mathrm{C}$.

Actually, these home-made resonators (see Fig. 1) are doubly-rotated cuts well-known as stress-compensated (SC)-cuts, ${ }^{9}$ packaged in a so-called BVA ("Boîtier à Vieillissement Amélioré:" improved aging holder) structure: the electrodeless and polished vibrating part is mechanically iso-

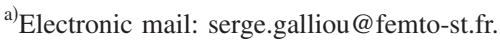

lated from its surrounding part by means of bridges in the same material. ${ }^{10}$

When encapsulated under vacuum, such a $10 \mathrm{MHz}$ third overtone (OT) $\mathrm{C}$-mode $\mathrm{SC}$-cut resonator exhibits a typical unloaded $Q$-factor close to $1.2 \times 10^{6}$ at room temperature, and its flicker noise level ${ }^{11-13}$ is characterized by a mean power spectral density of fractional frequency fluctuations of $S_{y}(1 \mathrm{~Hz})=-250 \mathrm{~dB} \mathrm{~Hz}^{-1}$.

The experimental set up core consists of a pulse-tube cryocooler which head is inside a vacuum chamber (see Fig. 2 ). Various inputs and outputs cables exist for monitoring the temperature of the cold head or feeding the resonators under test. The resonators are inserted into a piece of oxygen-free copper fixed to the second stage of the pulse-tube head.

Thermal losses are minimized thanks to an antiradiation shield, and the cables are successively temperaturecontrolled at the intermediate temperatures of both stages before going out. An external remote controller manages the power dissipation of a heater associated to a sensor at the second stage level. Then, the resonator temperature is locked around the set temperature with remaining fluctuations of $\pm 2 \mathrm{mK}$.

A network analyzer linked to a frequency reference $(\mathrm{H}-$ Maser) and equipped with its impedance test adapter is used to get directly the complex admittance of the tested resonator. This simple method has been preferred to the conven-

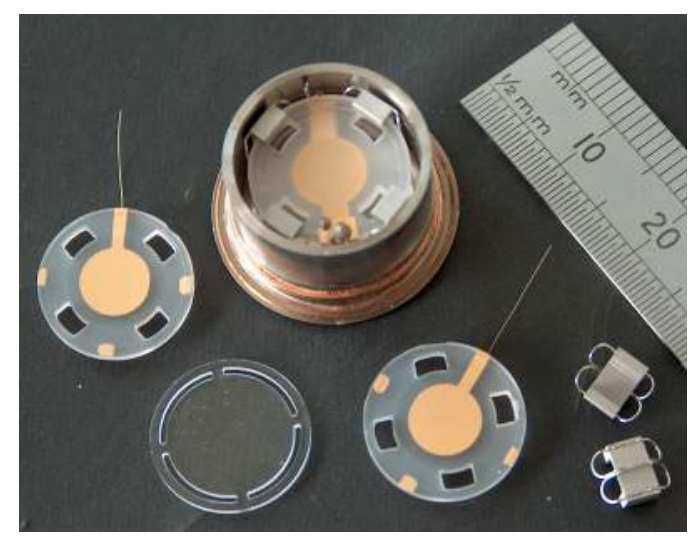

FIG. 1. (Color online) A home-made BVA-type resonator. The planoconvex resonator is pinched between two disks that support both electrodes. Vibration energy is trapped thanks to the resonator curvature radius. 


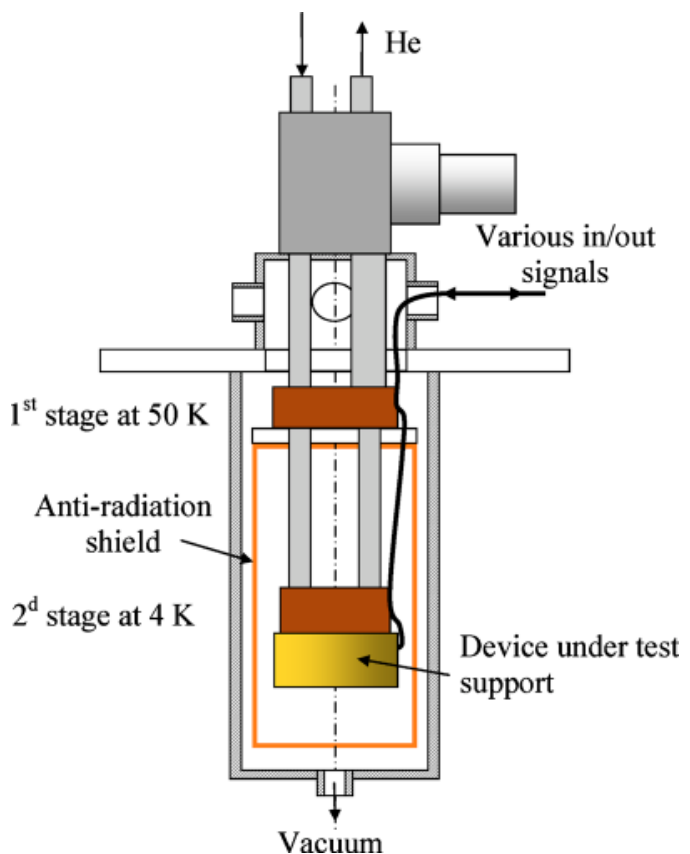

FIG. 2. (Color online) View of the experimental set up core.

tional $\pi$ network method because of the change in the resonator resistance with respect to temperature (it drops down from $100 \Omega$ at $300 \mathrm{~K}$ to less than $10 \Omega$ at $10 \mathrm{~K}$ ). The accuracy of the $Q$-factor measurement is evaluated to $4 \%$. Special precautions should be taken to cancel the feeding long cables which effects must be compensated. For the calibration, the three conventional references (open circuit, short cut, and $50 \Omega$ resistor) are put at the end of same cables as those of the resonator.

Moreover, resonators are excited at a low level in order to avoid non linear effects (amplitude-frequency effect).

A batch of resonators optimized to work at $10 \mathrm{MHz}$, on the third OT of their $\mathrm{C}$ mode at $85{ }^{\circ} \mathrm{C}$, have been systematically investigated. ${ }^{7}$ As expected the $Q$-factors of the C-mode (the slow quasitranverse vibration, i.e., a thickness shear mode) is improved under $20 \mathrm{~K},{ }^{14}$ but this is also the case with the B-mode (the fast quasitransverse mode), and especially with the A-mode, the quasilongitudinal mode (or extensional one, along the axis perpendicular to the thickness of resonator). $Q$-factors greater than 100 millions have been achieved at $3.3 \mathrm{~K}$, at a resonance frequency of $f=31 \mathrm{MHz}$, with these $10 \mathrm{MHz}$ resonators (resonator no. 1 in Fig. 3).

The vibration energy is more trapped in resonators optimized to get $5 \mathrm{MHz}$ on their $\mathrm{C}$-mode third OT at $85^{\circ} \mathrm{C}$ than in $10 \mathrm{MHz}$ resonators. Recorded data of such $5 \mathrm{MHz}$ resonators are shown in Fig. 3 (resonator no. 2). It exhibits the same trend of $1 / Q$ versus temperature $T$ as $10 \mathrm{MHz}$ resonators but the best result is a $Q$-factor of 325 millions at $4 \mathrm{~K}$, still reached with the A mode fifth OT at $f=15.9 \mathrm{MHz}$ mode.

Theoretically, when $2 \pi f \tau_{t h}>1\left(\tau_{t h}\right.$ being the thermal phonon lifetime) as it is the case here, losses are mainly due to the phonon-phonon scattering mechanism according to the Landau-Rumer's regime stating that $1 / Q$ is proportional to $T^{4} \cdot{ }^{15-17}$ Actually, this behavior is not strictly verified but is closer to $1 / Q \approx a \times T^{n}$ — constant, $a$ being a constant, with $n$ close to 4 for the quasitransverse modes, and 6 for the quasi-

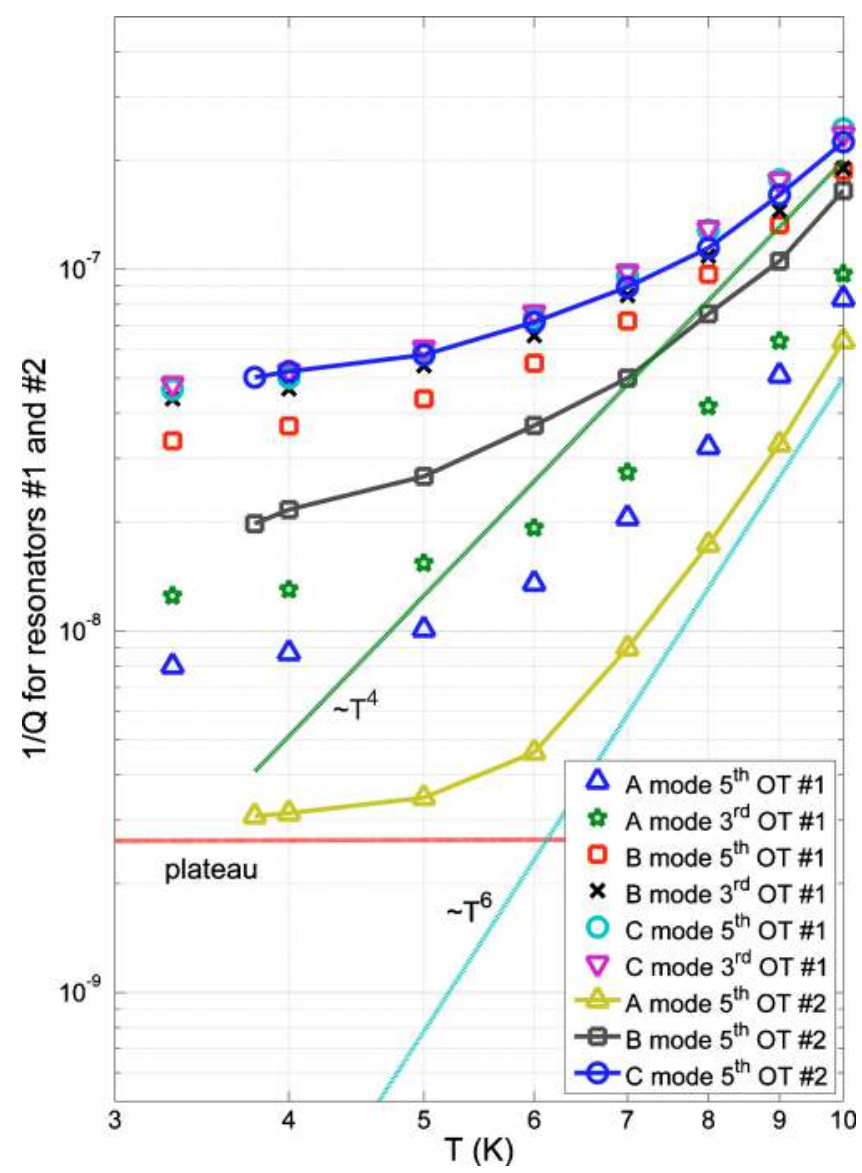

FIG. 3. (Color online) $1 / Q$ vs temperature for resonator no. 1 and resonator no. 2. Originally, resonator no. 1 is optimized to work at a resonance frequency of $10 \mathrm{MHz}$ at $85^{\circ} \mathrm{C}$, and resonator no. 2 at $5 \mathrm{MHz}$, both on the third OT of their C-mode. From top to bottom of the legend, measured frequencies (in $\mathrm{MHz}$ ) are, respectively: 31.26 (A mode fifth OT), 18.77 (A mode third OT), 18.38 (B mode fifth OT), 10.98 (B mode third OT), 16.60 (C mode fifth OT), 9.98 (C mode third OT), for resonator no. 1 , and 15.59 (A mode fifth OT), 9.19 (B mode fifth OT), 8.40 (C mode fifth OT) for resonatorno. 2 .

longitudinal mode. Losses varying as $T^{n}$ with $n>4$ have already been observed. ${ }^{16,18}$

The fact that the $Q$-factor becomes a constant as temperature decreases could originate in various mechanisms of losses ${ }^{17,19}$ such as acoustic diffraction at the resonator's surface (due to its roughness and/or the existence of an amorphous layer due to machining and polishing) and/or damping at the edge of the resonant disk (due to a default of vibration trapping), etc. From the Stevens and Tiersten's model, ${ }^{8}$ the computation of the ratio of vibration amplitude at the edge of the resonant disk, in comparison with the vibration amplitude at its center, gives the results shown in Table I: when sorting out them from the best trapped mode to the less trapped one,

TABLE I. Calculated ratio of vibration amplitude at the edge over the one at its center, for a device originally optimized to exhibit a resonance frequency of $10 \mathrm{MHz}$ at $85^{\circ} \mathrm{C}$. For the vibration trapping, the planoconvex resonator used in this work has a radius of curvature of $230 \mathrm{~mm}$.

\begin{tabular}{lccc}
\hline \hline OT & $\begin{array}{c}\text { A-mode } \\
\text { (quasilongitudinal) }\end{array}$ & $\begin{array}{c}\text { B-mode } \\
\text { (fast quasishear) }\end{array}$ & $\begin{array}{c}\text { C-mode } \\
\text { (slow quasishear) }\end{array}$ \\
\hline Third & $1 \times 10^{-14}$ & $1 \times 10^{-7}$ & $3 \times 10^{-7}$ \\
Fifth & $3 \times 10^{-21}$ & $7 \times 10^{-12}$ & $2 \times 10^{-10}$ \\
\hline \hline
\end{tabular}


ranks are the same as $1 / Q$ for resonator no. 1 in Fig. 3. By the same way, a better trapped resonator like resonator no. 2 exhibits a plateau at lower level for a given mode and OT. This proves that the trapping default is probably the dominant loss mechanism at low temperature.

In addition, it can be noticed that for a given mode, losses in resonator no. 1 are approximately the same as in resonator no. 2 , in the region where the trapping default is not too much dominant (at $10 \mathrm{~K}$, for example), i.e., the intrinsic $Q$-factor does not depend of $f$, in agreement with the Landau-Rumer's theory.

As a conclusion, a $Q$-factor probably close to the intrinsic quartz crystal $Q$-factor is achievable from measurements of modes well-trapped in bulk acoustic wave resonators. It is also verified that their behavior is ideally close to the Landau-Rumer's regime in the described experimental conditions. Otherwise, the dominant limitation seems to be a trapping default.

This work is partly supported by Région de Franche Comté No. 2008C_16215, France.

${ }^{1}$ R. Nawrodt, C. Schwarz, D. Heinert, M. Thürk, R. Neubert, W. Vodel, A. Tünnermann, and P. Seidel, Cryogenic Setup for Q-factor measurements on bulk materials for future gravitational wave detectors, Proceedings of ICEC 22-ICMC 2008, edited by H.-M. Chang et al. (The Korea Institute of Applied Superconductivity and Cryogenics, Korea, 2009), p. 519-524. ${ }^{2}$ A. Zimmer, R. Nawrodt, D. Heinert, C. Schwarz, M. Hudl, T. Koettig, W. Vodel, A. Tünnermann, and P. Seidel, J. Phys.: Conf. Ser. 92, 012095 (2007).

${ }^{3}$ A. Zimmer, R. Nawrodt, T. Koettig, R. Neubert, M. Thürk W. Vodel A.
Tünnermann, and P. Seidel, Rev. Sci. Instrum. 78, 063905 (2007).

${ }^{4}$ A. Grib, D. Heinert, R. Nawrodt, C. Schwarz, V. Große, P. Seidel, I. Martin, S. Rowan, and J. Hough, J. Appl. Phys. 107, 013504 (2010).

${ }^{5}$ P. Salzenstein, A. Kuna, L. Šojdr, and J. Chauvin, Electron. Lett. 46, 1433 (2010)

${ }^{6}$ M. Planat and J. J. Gagnepain, Appl. Phys. Lett. 50, 510 (1987).

${ }^{7}$ S. Galliou, J. Imbaud, R. Bourquin, N. Bazin, and P. Abbé, Electron. Lett. 44, 889 (2008).

${ }^{8}$ D. S. Stevens, and H. F. Tiersten, J. Acoust. Soc. Am. 79, 1811 (1986).

${ }^{9}$ E. P. Eernisse, Quartz Resonator Frequency Shifts Arising from Electrode Stress, Proceedings of 29th Annual Frequency Control Symposium, Fort Monmouth, NJ (Electronic Industries Association, Washington, DC, 1975), pp. 1-4.

${ }^{10}$ R. J. Besson, A new electrodeless resonator design, Proceedings of $31 \mathrm{st}$ IEEE Annual Frequency Control Symposium, Fort Monmouth, NJ (Electronic Industries Association, Washington, DC, 1977), pp. 147-152.

${ }^{11}$ F. L. Walls, P. H. Handel, R. Besson, and J. J. Gagnepain, A New Model of I/f Noise in BAW Quartz Resonators, Proceedings of 1992 IEEE Frequency Control Symposium, Hershey, PA (IEEE, Piscataway, NJ, 1992), pp. 327-333.

${ }^{12}$ E. Rubiola, J. Groslambert, M. Brunet, and V. Giordano, IEEE Trans. Ultrason. Ferroelectr. Freq. Control 47, 361 (2000).

${ }^{13}$ V. F. Kroupa, Phys. Lett. A 336, 126 (2005).

${ }^{14}$ J. J. Suter, J. Appl. Phys. 63, 5594 (1988).

${ }^{15}$ L. Landau and G. Rumer, Phys. Z. Sowjetunion 11, 18 (1937).

${ }^{16}$ H. J. Maris, in Physical Acoustics, edited by R. N. Thurston and W. P. Mason (Academic, New York, 1971), Vol. III, pp. 279-345.

${ }^{17} \mathrm{~A}$. El Habti, "Study of resonators and oscillators at very low temperatures," Ph.D. thesis, Université de Franche Comté, 1993 (in French).

${ }^{18}$ M. F. Lewis and E. Patterson, Phys. Rev. 159, 703 (1967).

${ }^{19} \mathrm{R}$. Tabrizian, M. Rais-Zadeh, and F. Ayazi, Effect of phonon interactions in limiting the $f, Q$ product of micromechanical resonators, Proceedings of the 15th International Conference on Solid-State Sensors, Actuators and Microsystems Conference, Transducers 2009 (IEEE, Piscataway, NJ, 2009), 2131-2134. 